\title{
FIBROSE RETROPERITONEAL: TRATAMENTO VIDEOLAPAROSCÓPICO
}

Paciente masculino, 4l anos, branco, apresentando dor lombar bilateral há oito meses. Após três meses, notou edema de membros inferiores evoluindo para anasarca. Antecedente de traumatismo renal por trauma automobilístico há 17 anos, sendo instituído tratamento conservador. Exames laboratoriais evidenciaram uréia de $190 \mathrm{mg} / \mathrm{dl}$ e creatinina sérica de $17 \mathrm{mg} / \mathrm{dl}$, sendo instituída hemodiálise de urgência. A ecografia renal revelou discreta dilatação pielocalicial à direita e moderada à esquerda. Realizada ressonância magnética que evidenciou extensa placa fibrótica retroperitoneal, com proliferação de partes moles, captante de contraste, envolvendo a aorta, veia cava, vasos ilíacos e causando encarceramento ureteral bilateral (Figuras I e 2) sugestivo de fibrose retroperitoneal.

Realizou-se desobstrução ureteral endoscópica bilateral com cateter duplo jota, com resolução do quadro doloroso, sendo proposto ureterólise por via lapa roscópica. 0 tratamento foi realizado em dois tempos operatórios distintos, sendo realizada biópsia de congelação intra-operatória, a qual não revelou presença de neo plasia. Após liberação do ureter, procedeu-se a intraperitonização do mesmo com retalho de grande omento. O paciente recebeu alta no segundo dia pós-operatório de cada procedimento, com creatinina de $1,8 \mathrm{mg} / \mathrm{dl}$ e uréia de 38 $\mathrm{mg} / \mathrm{dl}$. Exame histopatológico foi compatível com fibrose retroperitoneal (FR) idiopática. Os cateteres ureterais foram retirados após duas semanas da segunda cirurgia e o paciente encontra-se em acompanhamento ambulatorial há 1,5 ano, sem evidências de recidiva e com níveis de uréia e creatinina normais.

\section{DISCUSSÃO}

Fibrose retroperitoneal (FR) é doença rara, predominante em homens (3:I). A etiopatogenia permanece incerta, apesar da resposta inflamatória sugerir processo imune. A doença pode ser secundária a neoplasias, agentes infecciosos e uso de medicamentos como a metisergida. Os principais sintomas são relacionados ao trato urinário.

O acometimento retroperitoneal, às imagens radiológicas, estende-se do hilo renal até a borda da pelve. A urografia excretora demonstra retardo da eliminação do contraste, hidronefrose e desvio medial dos ureteres. A tomografia computadorizada é o exame de escolha para o diagnóstico, sendo a ressonância magnética utilizada nos casos que se apresentam com insuficiência renal. Para o tratamento clínico, as drogas mais utilizadas são os corticoesteróides, como a prednisolona. Drogas imunossupressoras têm sido empregadas como a ciclofosfamida, metotrexato e o tamoxifeno.

Muitas vezes o tratamento cirúrgico se impõe sendo este de elevada morbidade. Este consiste na exploração abdominal, realização de biópsias e ureterólise, sendo efetivo em $90 \%$ dos casos. No intuito de dimimuir a morbidade do tratamento cirúrgico, a videolaparoscopia apresenta-se como alternativa. promovendo menor dor pós-operatória, menor tempo de inter nação e de convalescência, bem como melhor resultado cosmético.

Desta forma, a FR primária ou secun dária é entidade rara. Quanto ao trata mento clínico, não se sabe ainda seus reais benefícios. $O$ uso da laparoscopia para realização da ureterólise demonstra-se uma excelente alternativa, permitindo adequado diagnóstico e tratamento, com dimi nuição da morbidade do procedimento.

Thais Alencar Pinto dos Santos, Roberto Ribeiro Maroccolo,

Fernando Augusto ferreira Diaz, Eduardo Carvalho Ribeiro,Romulo MAROCCOLO FILHO

Serviço de Urologia, Hospital UNIVERSITÁRIO DE BRASÍLIA (HUB), UNIVERSIDADE DE BRASÍLIA (UNB), BRASÍLIA - DF

\section{Figura I - Ressonância magnética evidenciando dilatação pielocalicial e encarceramento ureteral bilateral}



Figura 2 - Extensão da placa fibrótica retroperitoneal com acometimento dos grandes vasos e dos ureteres

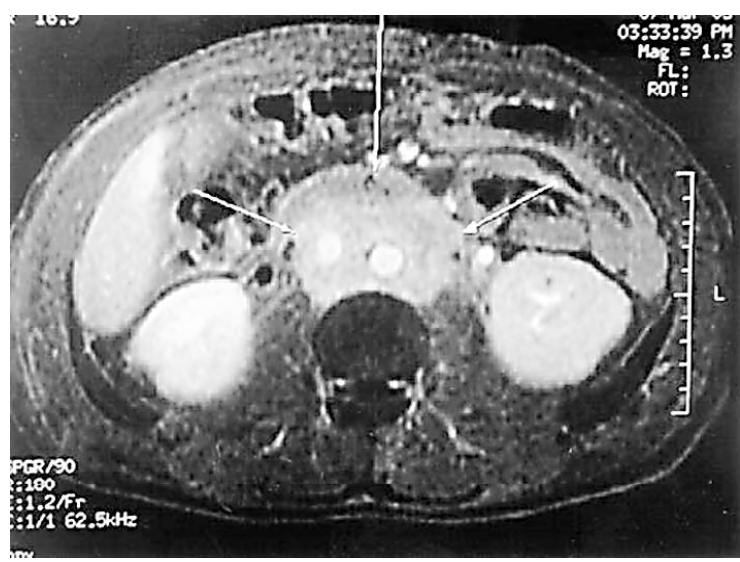

